\title{
Level of unintended pregnancy among reproductive age women in Bahir Dar city administration, Northwest Ethiopia
}

\author{
Eleni Admasu, Alemtsehay Mekonnen, Tesfaye Setegn and Gedefaw Abeje*
}

\begin{abstract}
Objective: The objective of this study was to determine the prevalence and determinants of unintended pregnancy among reproductive age women in Bahir Dar town, Northwest Ethiopia.

Result: The prevalence of unintended pregnancy was 15.8\% (95\% Cl 13.8\%-17.7\%). Single women (AOR 0.18; $95 \%$ $\mathrm{Cl}$ 0.08-0.40), women living away from their husband (AOR 4.18; 95\% Cl 2.64-6.61) and women with no access/exposure to mass-media (AOR 1.89; $95 \% \mathrm{Cl} 1.13-3.15$ ) were more likely to have unintended pregnancy compared to their counter parts.
\end{abstract}

Keywords: Unintended pregnancy, Bahir Dar, Mass media

\section{Introduction}

Unintended pregnancy is identified as pregnancy either mistimed or unwanted at a time of conception regardless of women's contraceptive use [1]. A pregnancy is assumed mistimed if a woman became pregnant at a time when she did not want to. On the other hand, pregnancy is assumed unwanted if the woman did not intend to ever become pregnant, or if the pregnancy occurred when she wanted to have no more children [2]. Some of the leading causes of unintended pregnancies include not using contraceptives, contraceptive failure and less commonly rape [3].

Unintended pregnancy is a public health problem which affects maternal and child health $[4,5]$. In 2012, about $40 \%$ of the estimated 213 million pregnancies were unplanned [6]. In Sub-Saharan Africa, approximately 14 million unintended pregnancies occur every year [7]. According to the 2011 Ethiopian Demographic and Health Survey (EDHS) report, 32\% of pregnancies at the time of survey were reported unintended [8]. Other studies in the Eastern and Southern part of Ethiopia

\footnotetext{
*Correspondence: abejegedefaw@gmail.com
}

Department of Reproductive Health, School of Public Health, College

of Medicine and Health Sciences, Bahir Dar University, Bahir Dar, Ethiopia also showed high proportion of unintended pregnancy [9-11].

Although unintended pregnancy has social, cultural and health impacts, especially for the mother and the fetus, little is known about the prevalence and associated factors of unintended pregnancy among women in Bahir Dar. Therefore, the aim of this study was to determine the prevalence and identify determinants of unintended pregnancy among women in Bahir Dar town.

\section{Main text Methods}

A community based cross-sectional study was conducted among reproductive age women in Bahir Dar city administration. The city administration is located $565 \mathrm{~km}$ Northwest of Addis Ababa, the capital city of Ethiopia. Bahir Dar is located at $565 \mathrm{~km}$ from Addis Ababa, capital of Ethiopia and administratively divided into 9 urban and 12 rural Kebeles (the smallest administrative unit in Ethiopia). There are 10 health centers and three hospitals (one government and two private hospitals), which provides maternal and child health services including family planning service [12].

The study included 680 pregnant women or women with under-1 year old child at the time of the study. Sample size was determined using single population 
proportion formula considering 95\% confidence level, 5\% margin of error and $27.9 \%$ estimated prevalence of unintended pregnancy (9). Finally after adding $10 \%$ of the calculated sample size for non-responses and using design effect of 2, the sample size was determined to be 680 . From the total of 10 kebeles, 7 Kebeles were selected randomly. The total sample size was proportionally allocated to each kebeles and individual women were selected using systematic random sampling technique using the maternal registration book (prepared by community health extension workers) as a sampling frame.

The data were collected by five trained nurses (supervised by two midwives) using a structured interviewer administered questionnaire (Amharic version-local language). The questionnaire was developed after reviewing relevant literatures (Additional file 1). Pretest was done to check the validity and consistency of the questionnaire.

Data was entered, cleaned and analyzed using SPSS version 20 statistical software. Both descriptive and analytical analyses were carried out. The woman was considered having unintended pregnancy if she reported if her recent birth or current pregnancy was mistimed or unwanted. Exposure to mass-media was considered if the woman had TV or radio at home. Bivariate and multivariable logistic regression analyses were carried out to identify the presence of statistical significance between the outcome variable with each independent variable. Statistical differences were considered at $\mathrm{p}<0.05$ and the strength of association was assessed by odds ratio (OR) with the respective confidence intervals.

Ethical clearance was obtained from the Ethical Review Committee (ERC) of Bahir Dar University, College of Medicine and Health Sciences. Permission letter was obtained from Amhara National Regional State (ANRS) Health Bureau and Bahir Dar city administration health office. Verbal consent was obtained from each study participants after they were informed about the purpose and objective of the study. They were also assured that they have the right to decline from answering the whole or parts of question they assume private.

\section{Result}

\section{Socio demographic characteristics of women}

From a total of 680 women, 674 (91\% response rate) were interviewed and included in the analysis. Six women were not found at the time of the study even with repeated attempts. Fifty-five questionnaires were not included in the analysis because there were inconsistencies.

The mean $( \pm \mathrm{SD})$ age of the women was $28.2( \pm 5.8)$ years. Majority $(84 \%)$ of women were urban residents. About fifty-six percent (56.4\%) of the respondents were married of which $57.7 \%$ reported that their marriage was arranged by their family. More than eighty-three percent
(83.5\%) of women were Orthodox Christians and 97.6\% were from Amhara ethnic group. About $60 \%$ of women reported that they were housewives. Nearly $40 \%$ women did not attend formal education (Table 1). In our study, $88.7 \%$ and $94.3 \%$ of the women reported that they were autonomous to visit their family and health institutions respectively. Ninety-eight percent (98\%) women reported that they have access to health institution with family planning service within $1 \mathrm{~h}$ walking distance.

\section{Obstetric characteristics of respondents and level of unintended pregnancy}

In our study, majority $(89.3 \%)$ of the participants got pregnant for the first time at after 18 years old. Sixty-nine percent $(69.1 \%)$ of women were multipara. About $86 \%$ of

Table 1 Socio demographic characteristics of women in Bahir Dar city administration, February-March, 2015

\begin{tabular}{lc}
\hline Variable & Number (\%) \\
\hline Age in years & \\
$\leq 25$ & $243(39.3)$ \\
$26-34$ & $258(41.7)$ \\
$\geq 35$ & $118(19.1)$ \\
Marital status & \\
Single & $66(10.7)$ \\
Married & $535(86.4)$ \\
Divorced/widowed & $18(2.9)$ \\
Religion & \\
Orthodox & $517(83.5)$ \\
Catholic and protestant & $21(3.4)$ \\
Muslim & $81(13.1)$ \\
Mother's occupation & \\
Housewife & $375(60.6)$ \\
Employee & $92(14.9)$ \\
Small business & $75(12.1)$ \\
Other* & $77(12.4)$ \\
Mother's educational status & \\
No formal education & $243(39.3)$ \\
Primary & $234(37.8)$ \\
Secondary and above & $142(22.9)$ \\
Husband occupation & $194(31.3)$ \\
Earmer & $233(37.6)$ \\
Merchant & $192(31.0)$ \\
Other* &
\end{tabular}

* Other = student, daily laborer 
Table 2 Determinants of unintended pregnancy in Bahir Dar town, Northwest Ethiopia, February-March, 2015

\begin{tabular}{|c|c|c|c|c|}
\hline \multirow[t]{2}{*}{ Variable } & \multicolumn{2}{|c|}{ Current/recent pregnancy } & \multirow[t]{2}{*}{ COR $(95 \% \mathrm{Cl})$} & \multirow[t]{2}{*}{ AOR $(95 \% \mathrm{Cl})$} \\
\hline & Intended & Unintended & & \\
\hline \multicolumn{5}{|l|}{ Age in years } \\
\hline$\leq 25$ & 196 & 47 & $1.33(0.74-2.41)$ & $1.29(0.51-3.26)$ \\
\hline $26-34$ & 225 & 33 & $0.85(0.44-1.52)$ & $0.88(0.39-1.95)$ \\
\hline$\geq 35$ & 100 & 18 & 1.0 & 1.00 \\
\hline \multicolumn{5}{|l|}{ Current living condition } \\
\hline With husband & 433 & 53 & 1.00 & 1.00 \\
\hline Living away from husband & 88 & 45 & $4.18(2.64-6.61)$ & $3.05(1.46-6.34)$ \\
\hline \multicolumn{5}{|l|}{ Family size } \\
\hline$\leq 6$ & 496 & 92 & $0.77(0.31-1.94)$ & $0.32(0.10-1.03)$ \\
\hline$>6$ & 25 & 6 & 1.00 & 1.00 \\
\hline \multicolumn{5}{|l|}{ Residence } \\
\hline Urban & 431 & 86 & $1.50(0.79-2.85)$ & $2.16(0.76-6.18)$ \\
\hline Rural & 90 & 12 & 1.00 & 1.00 \\
\hline \multicolumn{5}{|l|}{ Mother's occupation } \\
\hline Housewife & 326 & 49 & 1.00 & 1.00 \\
\hline Employee & 82 & 10 & $0.81(0.39-1.67)$ & $0.61(0.23-1.66)$ \\
\hline Small business & 64 & 11 & $1.14(0.56-2.32)$ & $1.80(0.73-4.43)$ \\
\hline Other & 49 & 28 & $3.80(2.19-6.61)$ & $2.06(0.94-4.53)$ \\
\hline \multicolumn{5}{|l|}{ Mother's educational status } \\
\hline No formal education & 197 & 46 & $1.72(0.94-3.13)$ & $1.63(0.65-4.08)$ \\
\hline Primary & 199 & 35 & $1.29(0.70-2.41)$ & $0.61(0.25-1.50)$ \\
\hline Secondary and above & 125 & 17 & 1.00 & 1.00 \\
\hline \multicolumn{5}{|l|}{ Autonomy to visit family } \\
\hline Autonomous & 462 & 87 & 1.00 & 1.00 \\
\hline Not autonomous & 59 & 11 & $0.99(0.50-1.96)$ & $0.39(0.14-1.11)$ \\
\hline \multicolumn{5}{|l|}{ Distance of HF from home } \\
\hline$\leq 1 \mathrm{~h}$ & 510 & 97 & 1.00 & 1.00 \\
\hline$>1 \mathrm{~h}$ & 11 & 1 & $0.48(0.06-3.75)$ & $0.99(0.10-9.42)$ \\
\hline \multicolumn{5}{|l|}{ Mass media available at home } \\
\hline Yes & 441 & 73 & 1.00 & 1.00 \\
\hline No & 80 & 25 & $1.89(1.13-3.15)$ & $2.81(1.27-6.23)$ \\
\hline \multicolumn{5}{|l|}{ Marital status } \\
\hline Single & 31 & 35 & 1.00 & 1.00 \\
\hline Married & 480 & 55 & $0.10(0.06-0.18)$ & $0.18(0.08-0.40)$ \\
\hline Widowed/divorced & 10 & 8 & $0.71(0.25-2.02)$ & $0.55(0.60-3.10)$ \\
\hline \multicolumn{5}{|l|}{ Gravidity } \\
\hline Primigravida & 176 & 48 & 1.00 & 1.00 \\
\hline Multigravida & 345 & 50 & $0.53(0.34-0.82)$ & $0.68(0.34-1.38)$ \\
\hline
\end{tabular}

women visited health facility for the current pregnancy while $10 \%$ of women reported that they had history of abortion. The study also showed that (48.6\%) of women (out of the total women who had under-1 year child) gave birth at health institutions. Seventy-five percent (75\%) of women reported ever use of contraceptives. But only $17.1 \%$ reported ever use of long acting contraceptive methods. In this study, the prevalence of unintended pregnancy was found to be $15.8 \%$ (95\% CI 13.8\%-17.7\%).

\section{Factors associated with unintended pregnancy}

Bivariate and multivariable logistic regression analysis was done with $95 \%$ CI to identify determinants of unintended pregnancy in Bahir Dar city administration. 
Nineteen variables were entered in the bivariate and multivariable logistic regression analysis but only marital status, living arrangement at the time of interview and availability of mass media at home remained significant in the bivariate and multivariable analysis (Table 2).

In this study married women were $82 \%$ less likely (AOR 0.18 ; 95\% CI $0.08-0.40$ ) to have unintended pregnancy compared single women. Women who were living away from their husband were about 4 times (AOR 4.18; 95\% CI 2.64-6.61) more likely to have unintended pregnancy compared to women who reported that they were living with their husband. Availability of mass media at home was an important predictor of unintended pregnancy. Women who reported that there was no mass media at home were about two times (AOR 1.89; 95\% CI 1.133.15) more likely to have unintended pregnancy compared to women who reported presence of mass media at home.

\section{Discussion}

In our study, the prevalence of unintended pregnancy was found to be 15.3 (95\% CI 13.8-17.7\%) for the current pregnancy or for the last birth women had. This finding is lower that national figure reported in the Ethiopian Health and Demographic Data [8]. Similarly, our finding is lower when compared with other research findings conducted in Ethiopia [11, 13]. This difference could be due to the difference in the scope, sample size, design and study period of the studies. For example, the national survey (EDHS, 2011) included both women from urban and rural settings proportionally. However, in our study, majority of participants were urban residents who could have better access to family planning services and including information.

Although the level of unintended pregnancy seems low in this study, compared to other findings in Ethiopia, different determinant factors could circumscribe the even and impact maternal health and neonatal/child health much. In this study, marital status of woman (being married) (AOR 0.18; 95\% CI 0.08-0.40), was found to be a significant factor for unintended pregnancy where married women were $82 \%$ less likely to have unintended pregnancy compared to single women. In the same fashion, studies conducted in Gelemso and Debremakos $[14,15]$ showed that married women have lesser risk to experience unintended pregnancy. This evidences showed the reverse that single women have higher risk of having unintended pregnancy. The probable reason for this could be that single women are more likely to have unplanned sexual activity and ashamed of using contraception, which leads them to have unintended pregnancy.

In the study, women who reported living away from their husband were 4 times (AOR 4.18; 95\% CI 2.64-6.61) more likely to have unintended pregnancy compared to women who reported living with their husband at the time of survey. The reason for this is that women who live away from their husband do not use contraceptives regularly due to irregular sexual intercourse. Similarly, women who reported no access to mass media at home were more likely (AOR 1.89; 95\% CI 1.13-3.15) to have unintended pregnancy compared to women who reported access. The reason for this may be women with access to mass media have better information about contraceptives and more likely to use family planning services. In conclusion, significant proportion of women have unintended pregnancy in Bahir Dar town although the magnitude is lower than previous studies done in different parts of Ethiopia. Single women, women who live away from their husband and women with no access to mass media are more likely to have unintended pregnancy.

\section{Limitations of the study}

Although the study identified some of the determinants of unintended pregnancy, the result may be affected by social desirability bias. Women tend to report that their pregnancy or recent birth is intended although the reality is different. The other limitation of the study is that this study may have missed women with unintended pregnancy who already aborted their pregnancy. This may underestimate the level of unintended pregnancy.

\section{Additional file}

Additional file 1. Questionnaire prepared to study determinants of unintended pregnancy among women in Bahir Dar city.

Authors' contributions

EA, AM, TS and GA involved in the design and development of its research proposal. They all were also involved in the data collection, analysis and interpretation of the findings. All authors read and approved the final manuscript.

\section{Acknowledgements \\ We would like to thank Bahir Dar University, College of Medicine and Health Sciences for funding this study. The authors would also like to thank data collectors, health extension workers and respondents of the study without whom this finding was impossible.}

Competing interests

The authors declare that they have no competing interests.

Availability of data and materials

The data sets analyzed for this study are available from the corresponding author on reasonable request.

Consent for publication

Not applicable. 


\section{Ethical approval and consent to participate}

Ethical clearance was obtained from the ethical review committee of college of medicine and health sciences, Bahir Dar University. Permission to conduct the study was obtained from Bahir Dar town health office. Written informed consent was obtained from each participant after explaining the objective of the study, their right to participate or not in the study and the risks and benefits of involvement in this study. The information collected from each participant was kept confidential using coding during data collection and putting the data in secure place.

\section{Funding}

This research was funded by Bahir Dar University. The university has no role in the analysis and interpretation of the findings.

\section{Publisher's Note}

Springer Nature remains neutral with regard to jurisdictional claims in published maps and institutional affiliations.

Received: 16 November 2018 Accepted: 12 December 2018

Published online: 14 December 2018

\section{References}

1. Indus B, Whitehead AN, Bensyl D. Pregnancy intention and contraceptive use among adult women. Maternal Child Health J. 2007;11(4):347-51.

2. Santelli J, Rochat R, Hatfield-Timajchy K, Gilbert BC, Curtis K, Cabral R, Hirsch JS, Schieve L. The measurement and meaning of unintended pregnancy. Perspect Sex Reprod Health. 2003; 3(2); 94-101. https://www. guttmacher.org/sites/default/files/article_files/3509403.pdf.

3. Casterline JB, ElZanatay F, El Zeni LO. Unmet need and unintended fertility: longitudinal evidence from Upper Egypt. Int Fam Plan Perspect. 2003:29(4):158-66.

4. Tiwari A, Chan KL, Fong D, Leung WC, Brownridge DA, Lam H, Wong B, Lam CM, Chau F, Chan A, Cheung KB, Ho PC. The Impact of psychological abuse by an intimate partner on mental health of pregnant women. BJOG. 2008;115:377-84.
5. Afable-Munsuz A, Braveman P. Pregnancy intention and preterm birth: differential associations among a diverse population of women. Perspect Sex Reprod Health. 2008;40(2):66-73.

6. Sedgh $G$, Singh $S$, Hussain R. Intended and unintended pregnancies worldwide in 2012 and recent trends. Stud Fam Plann. 2014;45(3):301-14. https://doi.org/10.1111/j.1728-4465.2014.00393.x.

7. Huacher D, Mavranezouli I, McGinn E. Unintended pregnancy in subSaharan Africa: magnitude of the problem and potential role of contraceptive implants to alleviate it. Contraception. 2008:78(1):73-8.

8. Central statistics agency [Ethiopia] and ICF International. Ethiopia demographic and health survey. Ethiopia: Central Statistical Agency and ICF International; 2011. p. 2012

9. Kassa N, Berhane Y, Worku A. Predictors of unintended pregnancy in Kersa, Eastern Ethiopia 2010. Reprod Health. 2012;9:1. https://doi. org/10.1186/1742-4755-9-1.

10. Hamdela B, Mariam A, Tilahun T. Unwanted pregnancy and associated factors among pregnant married women in Hosanna Town, Southern Ethiopia. PLoS ONE. 2012;1:1. https://doi.org/10.1371/journal.pone.00390 74

11. Worku S, Fantahun M. Unintended pregnancy and induced abortion in a town with accessible family planning services: the case of Harar, Eastern Ethiopia. Ethiop J Health Dev. 2006;20(2):79. https://doi.org/10.1016/j. contraception.2008.03.002.

12. Bahirdar Special Zone, Plan and Development Process, 2005 population projection report, Bahirdar, Ethiopia.

13. Dibaba Y. Child spacing and fertility planning among women in Mana District, Jimma, South West Ethiopia. Ethiop J Health Sci. 2010;20(2):83-90

14. Mohammed F, Musa A, Amano A. Prevalence and determinants of unintended pregnancy among pregnant women attending ANC at Gelemso General hospital, Oromia region, East Ethiopia; a facility based cross sectional study. BMC Women's Health. 2016;16:56.

15. Kibret A, Bayu H, Merga M. Prevalence of unintended pregnancy and associated factors among pregnant women attending antenatal clinics in Debre-markos Town, North West Ethiopia 2012. J Women's Health Care. $2014 \cdot 4 \cdot 3$
Ready to submit your research? Choose BMC and benefit from:

- fast, convenient online submission

- thorough peer review by experienced researchers in your field

- rapid publication on acceptance

- support for research data, including large and complex data types

- gold Open Access which fosters wider collaboration and increased citations

- maximum visibility for your research: over $100 \mathrm{M}$ website views per year

At $\mathrm{BMC}$, research is always in progress.

Learn more biomedcentral.com/submissions 